\title{
NUMERICAL STUDY ON THE EFFECT OF TUNNEL ASPECT RATIO ON THE PLUG-HOLING PHENOMENA IN SHALLOW UNDERGROUND TUNNELS
}

\author{
KI-BAE HONG ${ }^{1}$, JUNYOUNG NA ${ }^{2}$, KUN HYUK SUNG ${ }^{2}$ \& HONG SUN RYOU \\ ${ }^{1}$ Korea National University of Transpiration, South Korea \\ ${ }^{2}$ Chung-Ang University, South Korea
}

\begin{abstract}
Natural ventilation systems (NVS) have been widely used in shallow underground tunnels due to convenience in installation, maintenance and low cost compared with mechanical ventilation systems. In the NVS, smoke ventilation rate is mainly determined by the flow rate through the vertical shaft due to the stack effect. In practice, fresh air under smoke layer directly flows into the shaft and the phenomena is defined as "plug-holing". When the plug-holing occurs in the NVS, the actual smoke ventilation rate becomes smaller than the design value. The plug-holing phenomenon correlates relative ratio between ceiling jet flow and buoyant flow immediately below the shaft. Therefore, tunnel geometrics and fire size mainly affect the plug-holing phenomena. Especially, the area of the ceiling plays an important role in the properties of smoke layer such as temperature and velocity, thus the crosssectional aspect ratio of a tunnel can affect the occurrence of plug-holing. In this study, we numerically investigated the effect of tunnel aspect ratio on the plug-holing phenomena in shallow underground tunnels. Numerical analysis was performed with changing the tunnel aspect ratio which is defined as the ratio of the height to width of tunnel. As a result, as the aspect ratio decreases, the velocity and temperature of the smoke layer decreases and it means that the buoyancy and momentum force are diminished. The momentum force decreases more rapidly than the buoyancy force, so the fresh air can be entrained into the shaft. Therefore, the potential for the occurrence of plug-holing increases as the aspect ratio decreases.
\end{abstract}

Keywords: plug-holing, CFD.

\section{INTRODUCTION}

In tunnels fires, smoke and hot gas rapidly spread along the ceiling to the whole tunnel immediately after the fire. Also, evacuation routes are the same with the primary way that smoke spreads, which causes many human causalities due to toxic gas suffocation. In accordance with the reports by fire statics from NFPA (National Fire Protection Association) in USA, smoke inhalation and decreased visibility are the major causes of incurring casualties in fire accidents. $75 \%$ of all fire deaths are caused by smoke inhalation and $47 \%$ of survivors caught in fire. Also, over than $70 \%$ of casualties are caused by the suffocation effect due to the toxic gas from the fire [1]. Therefore, exhausting or controlling smoke is very important in ensuring the evacuation route in the fire cases.

Generally, smoke ventilation systems classified into mechanical ventilation systems (MVS) and natural ventilation systems (NVS) depending on how to exhaust smoke. The NVS, in which smoke is exhausted by the stack effect of a vertical shaft, have been widely used in shallow underground tunnels due to convenience in installation, maintenance and low cost compared with MVS. On the other hand, NVS is in capable of control the exhaust amount of smoke flow actively or artificially. This is because the buoyancy force of smoke mainly affects the performance of NVS related to the passive smoke exhaust [2]. Therefore, it is necessary to accurately calculate the maximum smoke discharge capacity of NVS at a tunnel design stage. 
In fire cases, the vertical flow, which is driven by buoyancy force of smoke, is affected by fire size and NVS geometrics, e.g. heat release rate (HRR), cross-sectional aspect ratio of tunnel/shaft, height of shaft, hydraulic diameter of tunnel, and so on. In addition, the plugholing phenomena is one of the influence factors for the performance of NVS. In practice, the fresh air under smoke layer directly flows into the shaft with the smoke and it is defined as "plug-holing" [3], thereby the actual amount of smoke exhaust becomes smaller than the design value when the plug-holing occurs in the NVS.

Many researches have been conducted to develop the prediction index for the occurrence of plug-holing in the NVS depending on various influence factors. Hinkley [3] initially introduced the plug-holing phenomenon and suggested the modified Froude number $\left(\mathrm{Fr}_{H}\right)$, which is defined as the ratio of momentum force and buoyancy force of the smoke, as the criterion on the occurrence of plug-holing. However, the height of shaft, which affects buoyancy force of smoke induced by the stack effect, is not considered in the Hinkley's criterion. Ji et al. [4] carried out the reduced-scale experiments to investigate the effect of shaft height and heat release rate on the plug-holing in NVS and suggested the modified Richardson number $\left(R i_{J}\right)$. Baek et al. [5], however, found that the both existing criterion are incapable to predict the occurrence of plug-holing accurately depending on the hydraulic diameter. In this study, we numerically investigated the effect of cross-sectional aspect ratio of tunnel on the plug-holing in a reduced-scale model tunnel.

\section{THEORETICAL BACKGROUNDS}

\subsection{Plug-holing phenomenon}

In the view of physics, the occurrence of plug-holing is determined by whether the fresh air flows into the shaft, and the phenomena is associated with the ratio of momentum force and buoyant force of the smoke flow under the shaft [6]. Fig. 1 shows the schematic for the occurrence of plug-holing in NVS. In tunnel fires, the fire plume, i.e. smoke, arises and then flows along the ceiling which is called as the ceiling jet flow. The smoke is eventually exhausted through the shaft and the fresh air is entrained into the shaft with the vertical flow with the exhausting smoke. The sunken area is formed by the smoke layer interface between the smoke flow and the fresh air. When the apex of the sunken area is located higher than the height of the tunnel, it is judged that the plug-holing occurs because the pure fresh air directly flows into the shaft. Here, the shape of sunken area is associated with the characteristics of the ceiling jet and the vertical flows. Consequently, the plug-holing phenomenon is significantly affected by the relative flow intensity between the ceiling jet and the shaft, that is, the ratio of horizontal momentum force to buoyancy force acting on the sunken area.

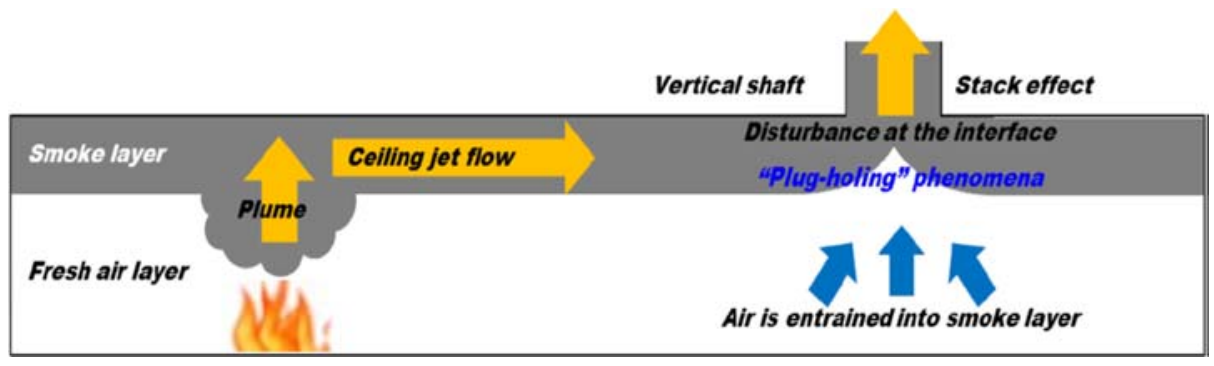

Figure 1: Schematic for the occurrence of plug-holing in the natural ventilation tunnel. (Source: Baek, 2017.) 


\subsection{Estimation of occurrence of plug-holing}

In this study, it is judged that plug-holing occurred in NVS when the smoke layer interface penetrates inside the shaft as shown in Fig. 2. Therefore, it is essential to define smoke layer interface and estimate temperature distribution in the interface plane. The temperature of smoke layer interface were calculated by using the Janssens and Tran model [7] from vertical temperature profile at $\mathrm{V}$-line which is $0.3 \mathrm{~m}$ away from the vertical center of shaft. Consequently, we considered that plug-holing occurred if there is a point in $\mathrm{H}$-line at which the temperature $\left(T_{s h}\right)$ is lower than that of smoke layer interface $\left(T_{s}\right)$, i.e. $T_{s h}<T_{s}$.

\section{NUMERICAL DETAILS}

\subsection{Modelling and grid generation}

A 1/20 reduced scale shallow tunnel was modelled for numerical study considering NVS. To changes the aspect ratio of tunnel cross-sectional area, only tunnel depth $\left(d_{t u}\right)$ changes from $0.3 \mathrm{~m}$ to $0.54 \mathrm{~m}$ when tunnel height $\left(h_{t u}\right)$ is fixed to $0.3 \mathrm{~m}$, so that five aspect ratios $(A R)$ i.e. $1.0,0.83,0.71,0.63$ and 0.57 , were selected as numerical cases as shown in Fig. 3. In addition, the shaft depth $\left(d_{s h}\right)$ changes from $0.1 \mathrm{~m}$ to $0.18 \mathrm{~m}$ depending on the AR while the ratio

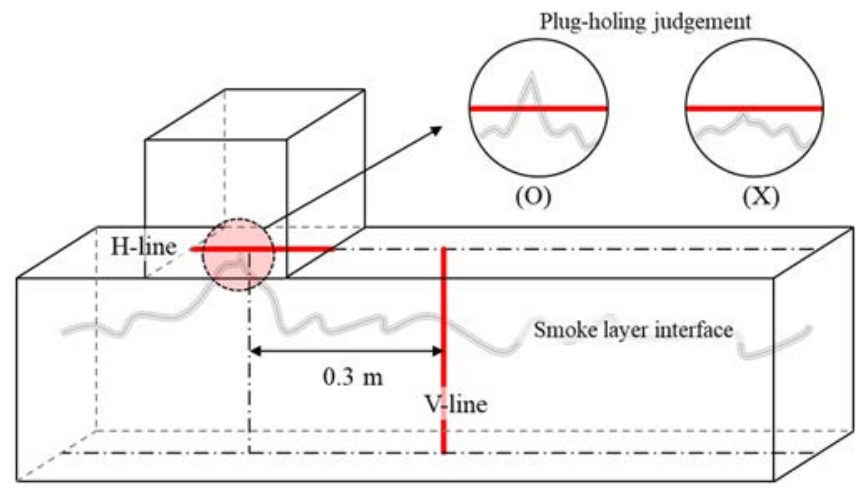

Figure 2: Schematics for judgement of plug-holing.

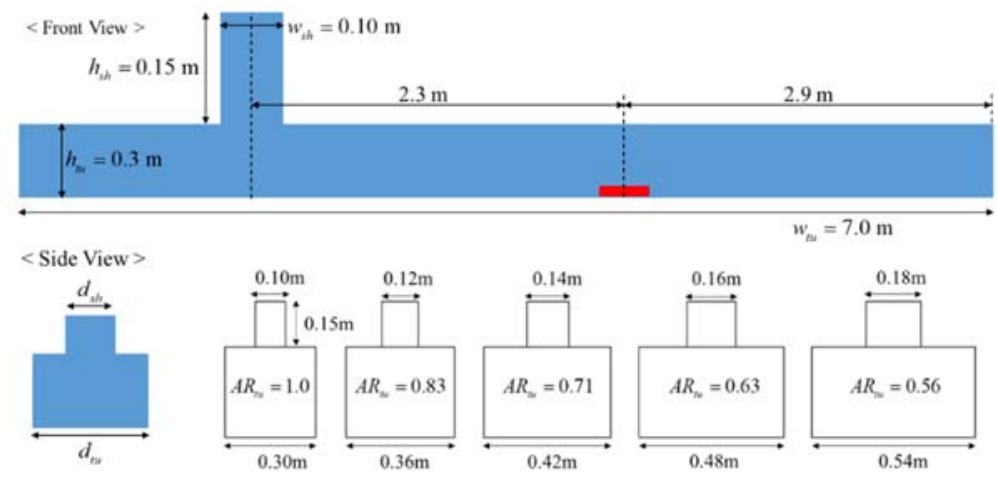

Figure 3: Schematics of reduced-scale model tunnel depending on the aspect ratio. 
of $d_{s h} / d_{t u}$ maintains at $1 / 3$. Shaft width $\left(w_{s h}\right)$ and shaft height $\left(h_{s h}\right)$ were fixed to $0.1 \mathrm{~m}$ and $0.15 \mathrm{~m}$, respectively.

Fig. 4 shows numerical domain and each grid size of different regions considering flow characteristics. The numerical domain was expended to ambient space around opening of shaft and tunnel to robust numerical convergence. The grid around the fire source is the densest in all cases, and the minimum grid size was determined by using the optimizing model for grid size considering heat release rate [8], [9]. As a result, the number of grid cells is around 350,000 for the whole cases and the cell size is $0.01 \mathrm{~m}$.

\subsection{Numerical and boundary conditions}

We calculated thermal and fluid flows in the model tunnel using Fire Dynamic Simulator (FDS) ver. 6.6, which is developed by National Institute of Standard and Technology (NIST) in USA. The FDS have been widely used to solve low-speed, thermally-driven flows with an emphasis on smoke and heat transfer from fires by using a large eddy simulation (LES). Transient analysis was performed to judge whether plug-holing occurs or not depending the aspect ratio in a quasi-steady state.

A heptane pool pane was located at $2.3 \mathrm{~m}$ away from the shaft and the heat release rate was fixed to $3.2 \mathrm{~kW}$ in all cases for the aspect ratio. No-slip and adiabatic conditions were applied to the whole wall. Pressure-outlet condition was used for all openings of tunnel and shaft. Ambient conditions for pressure and temperature are $1 \mathrm{~atm}$ and $11^{\circ} \mathrm{C}$, respectively, also initial condition was the same with the ambient condition.

\section{RESULTS AND DISCUSSION}

In this study, plug-holing phenomena was analysed with the mean values, i.e. temperature and velocity, during the quasi-steady state. So, each variable was averaged with the interval of $10 \mathrm{~s}$. We considered that thermal fluid flow in the tunnel reached the quasi-steady-state if there is a difference less than 5\% between mean values of the current interval and previous interval.

Fig. 5 shows temperature and velocity distribution in the V-line at the tunnel. Both of temperature and velocity increases as the aspect ratio increases, i.e. tunnel width becomes larger than tunnel height. In tunnel fire, hot gas flows along the ceiling to the openings of tunnel or shaft. Meanwhile, fresh air is entrained to the fire source. Consequently, the smoke layer interface is formed between hot gas and fresh air, and heat transfer occurs through the interface. Therefore, smoke layer temperature decreases with the aspect ratio due to an

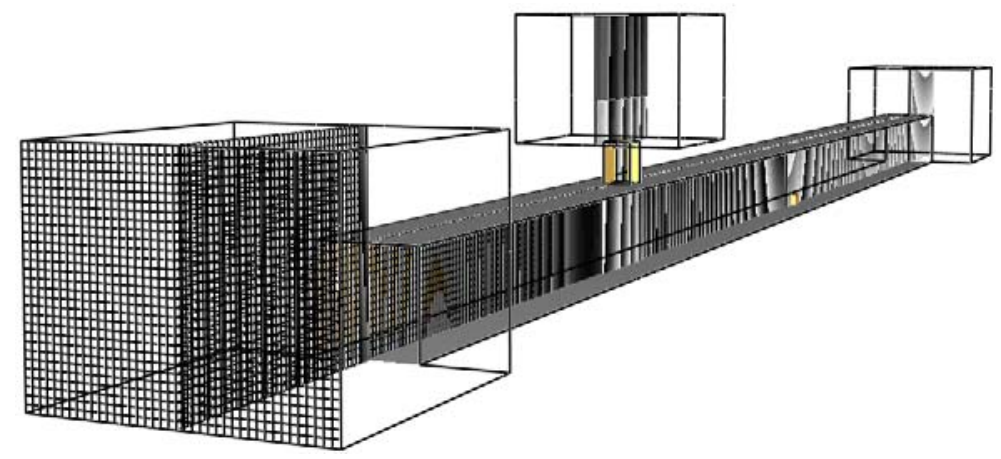

Figure 4: Numerical domain and grid. 
increase in the interface area. In addition, the momentum of ceiling flow decreases due to an increase in frictions at the wall, so smoke velocity decreases with the aspect ratio.

Fig. 6 shows temperature distribution in the H-line at the shaft. Temperature increases as the aspect decreases. This is because more hot gas flows into the shaft.

To judge the occurrence of plug-holing, the minimum temperature $\left(T_{\text {sh }}\right)$ in $\mathrm{H}$-line was compared with the temperature of smoke layer interface $\left(T_{s}\right)$ calculated from V-line. Plugholing occurs when $T_{s h}>T_{s}$. Smoke temperature and judgement of plug-holing depending on the aspect ratio are presented in Table 1. As the results, plug-holing does not occur in the only aspect ratio case of 1.0. It implies that the aspect ratio is one of the influence factor on

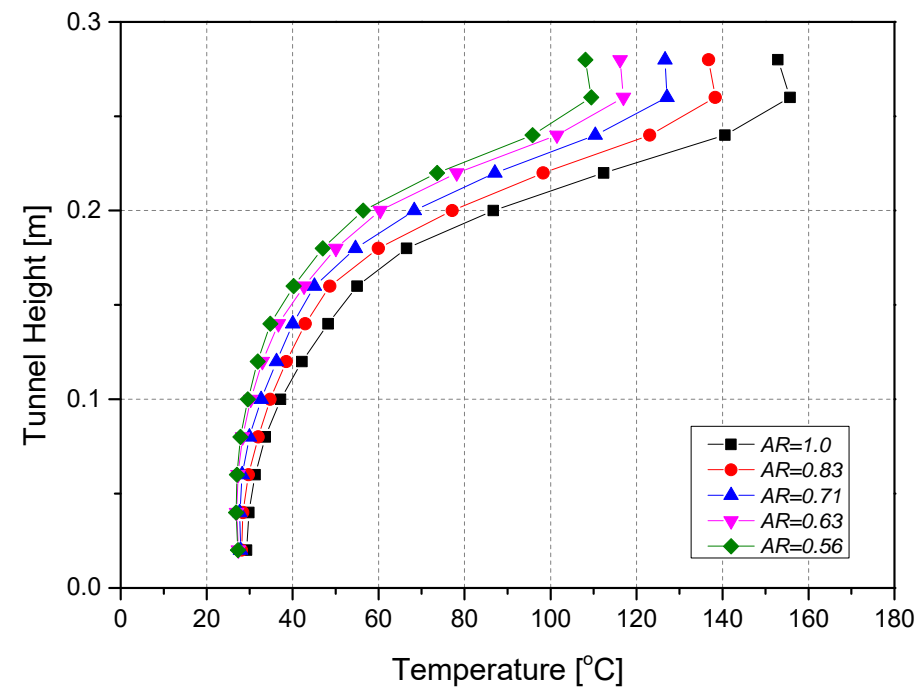

(a)

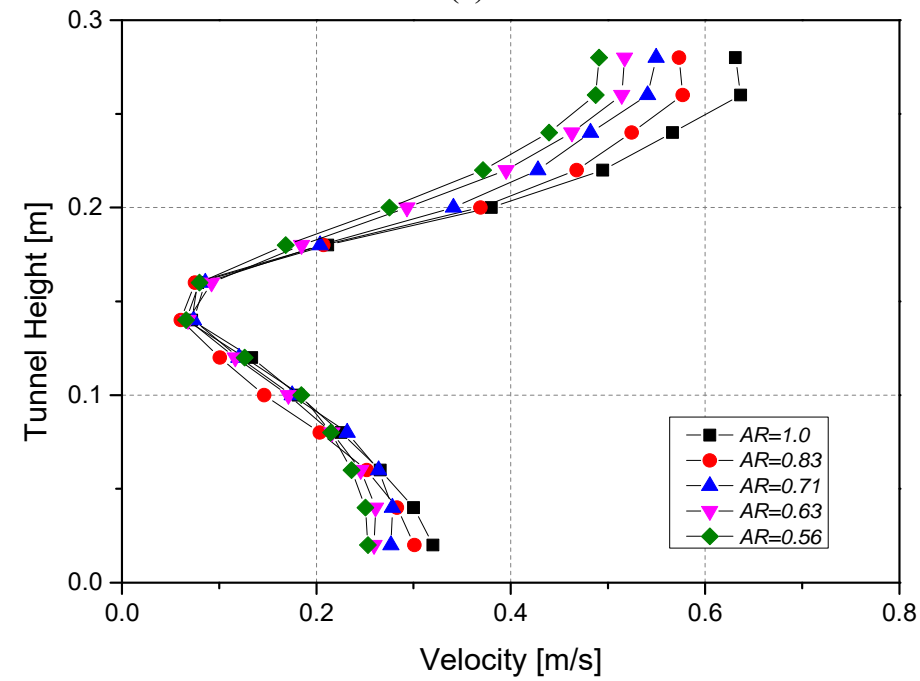

(b)

Figure 5: Profiles along V-line in the tunnel depending on aspect ratio. (a) Temperature; (b) Velocity. 


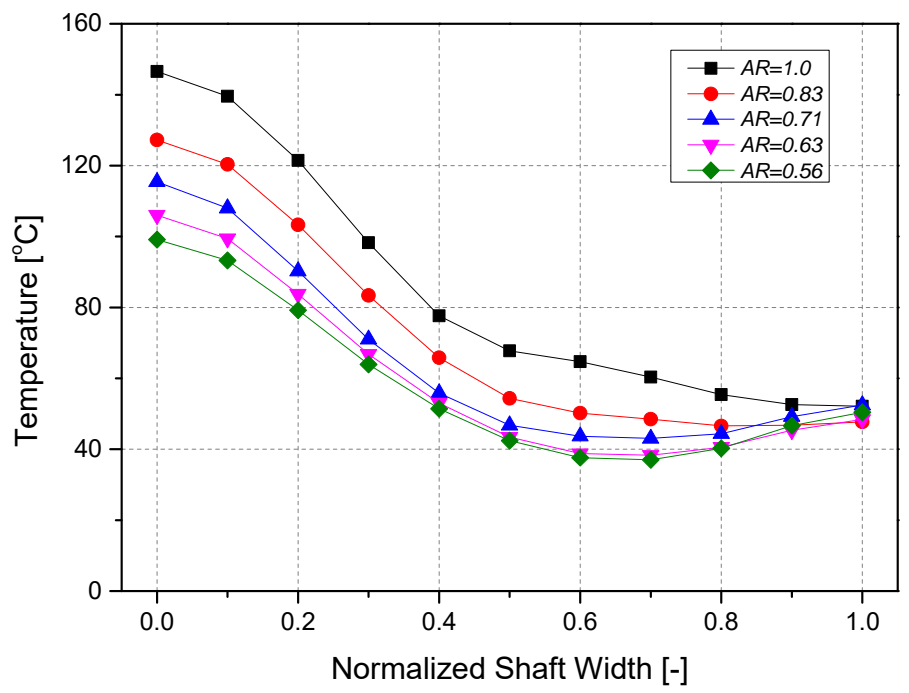

Figure 6: Temperature profile along H-line in the shaft depending on aspect ratio.

Table 1: Smoke temperature and plug-holing occurrence depending on the aspect ratio.

\begin{tabular}{|c|c|c|c|c|}
\hline $\begin{array}{c}\text { Aspect } \\
\text { ratio (AR) }\end{array}$ & $\begin{array}{c}\text { Smoke layer } \\
\text { interface height, } \\
h_{s}(\mathrm{~m})\end{array}$ & $\begin{array}{c}\text { Minimum } \\
\text { temperature in } \\
\mathrm{H} \text {-line, } T_{s h}\left({ }^{\circ} \mathrm{C}\right)\end{array}$ & $\begin{array}{c}\text { Temperature of } \\
\text { smoke layer } \\
\text { interface, } T_{s}\left({ }^{\circ} \mathrm{C}\right)\end{array}$ & $\begin{array}{c}\text { Plug-holing } \\
\text { occurrence }\end{array}$ \\
\hline 1.0 & 0.114 & 52.2 & 51.5 & $\mathrm{X}$ \\
\hline 0.83 & 0.117 & 46.6 & 46.8 & $\mathrm{O}$ \\
\hline 0.71 & 0.122 & 43.1 & 46.0 & $\mathrm{O}$ \\
\hline 0.63 & 0.131 & 38.3 & 46.1 & $\mathrm{O}$ \\
\hline 0.56 & 0.134 & 37.1 & 44.6 & $\mathrm{O}$ \\
\hline
\end{tabular}

the plug-holing phenomena. In addition, difference between $T_{s h}$ and $T_{s}$ becomes larger as the aspect ratio decreases, it means that the potential for occurrence of plug-holing increases.

\section{CONCLUSIONS}

In this study, we numerically the effect of the tunnel aspect ratio on the plug-holing phenomena with a constant heat release rate of $3.2 \mathrm{~kW}$.

- Temperature and velocity of smoke flow decreases with the aspect ratio;

- The potential for occurrence of plug-holing increases as the aspect ratio decreases.

In addition, parameter study for heat release rate and tunnel geometrics is essential to develop the prediction index for plug-holing phenomena as the further study.

\section{ACKNOWLEDGEMENTS}

This research was supported by Fire Fighting Safety \& 119 Rescue Technology Research and Development Program funded by the Ministry of Public Safety and Security ("MPSSFire Fighting-2015-80”). 


\section{REFERENCES}

[1] Alarie, Y., Toxicity of fire smoke. Crit. Rev. Toxicol., 32(4), pp. 259-289, 2002.

[2] Heskestad, G., Smoke distributions from fire plumes in uniform downdraft from a ceiling. Fire Safety Journal, 39(5), pp. 358-374, 2004.

[3] Hinkley, P., The flow of hot gases along an enclosed shopping mall a tentative theory. Fire Safety Science, 807, 1970.

[4] Ji, J. et al., A study of the effect of plug-holing and boundary layer separation on natural ventilation with vertical shaft in urban road tunnel fires. International Journal of Heat and Mass Transfer, 55(21-22), pp. 6032-6041, 2012.

[5] Baek, D., Bae, S. \& Ryou, H.S., A numerical study on the effect of the hydraulic diameter of tunnels on the plug-holing phenomena in shallow underground tunnels. Journal of Mechanical Science and Technology, 31(5), pp. 2331-2338, 2017.

[6] Baek, D., Sung, K.H. \& Ryou, H.S., Experimental study on the effect of heat release rate and aspect ratio of tunnel on the plug-holing phenomena in shallow underground tunnels. International Journal of Heat and Mass Transfer, 113, pp. 1135-1141, 2017.

[7] Janssens, M. \& Tran, H.C., Data reduction of room tests for zone model validation. Journal of Fire Sciences, 10(6), pp. 528-555, 1992.

[8] Bounagui, A. et al., Optimizing the grid size used in CFD simulation to evaluate fire safety in houses, 2003.

[9] McGrattan, K.B. et al., Improved radiation and combustion routines for a large eddy simulation fire model. Fire Safety Science, 7, pp. 827-838, 2003. 